\title{
UJI AKTIVITAS ANTIBAKTERI SERBUK INSTAN KOMBINASI TEMU MANGGA (Curcuma Mangga Val.) DAN DAUN ANTING-ANTING (Acalypha indica L.)
}

\author{
Putu Lakustini Cahyaningrum ${ }^{1}$, Ni Putu Rahayu Artini ${ }^{2}$ \\ ${ }^{1}$ Program Studi Kesehatan Ayurweda Fakultas Kesehatan, Universitas Hindu Indonesia \\ ${ }^{2}$ Program Studi Teknolog iLaboratorium Medik, Institut Ilmu Kesehatan Medika Persada Bali \\ Email : putulakustinicahyaningrum@gmail.com
}

\begin{abstract}
ABSTRAK
Penelitian ini bertujuan untuk mengetahui aktivitas antibakteri dari kombinasi dua tanaman yaitu temu mangga (Curcuma mangga Val.) dan daun anting-anting (Acalypha indica L.) yang diolah dalam bentuk minuman serbuk instan.Hal ini dilakukan agar memudahkan dan praktis dalam penyajian serta memiliki waktu simpan yang lebih lama. Langkah awal yang dilakukan yaitu proses pembuatan serbuk instan melalui kristalisasi. Dari proses kristalisasi diperoleh jumalah serbuk instan temu mangga dan daun anting-anting sebanyak 840 gram. Pengujian aktivitas antibakteri menggunakan metode difusi sumur (modifikasi kirby Bauer). Dari hasil penelitian diperoleh bahwa konsentrasi serbuk instan menunjukkan adanya aktivitas antibakteri pada konsentrasi $80 \%$ dan $100 \%$ dengan daya hambat yang tergolong kuat sedangkan pada konsentrasi $60 \%$ tergolong sedang dan pada konsentrasi $20 \%$ dan $40 \%$ tergolong lemah sebagai antibakteri.Peningkatan konsentrasi serbuk instan yang diberikan dari $20 \%, 40 \%, 60 \%, 80 \%$ dan $100 \%$ menunjukkan semakin besar diameter zona hambat yang terbentuk disekeliling sumur, karena semakin meningkatnya senyawa-senyawa berkhasiat dalam serbuk instan yang dapat menghambat pertumbuhan bakteri E.Coli.
\end{abstract}

Kata Kunci : aktivitas antibakteri, serbuk instan, Curcuma mangga Val, dan Acalypha indica L.

\section{ABSTRACT}

This study aims to determine the antibacterial activity of a combination of two plants, namely the meeting of mango (Curcuma mangga Val.) And earring leaves (Acalyphaindica L.) which are processed in the form of instant powder drinks. This is done to make it easy and practical in presentation and has a longer shelf time. The first step taken in the process of making instant powder through crystallization. During the crystallization process, there were 840 grams of instant powder meeting mango and earring leaves. Antibacterial activity testing using well diffusion method (modified by Bauer). The results showed that the concentration of instant powder showed antibacterial activity at concentrations of $80 \%$ and $100 \%$ with a relatively strong inhibitory power while at concentrations of $60 \%$ were classified as moderate and at concentrations of $20 \%$ and $40 \%$ were classified as weak as antibacterials. Increased concentrations of instant powder given from 20\%,40\%,60\%,80\% and $100 \%$ indicate the larger diameter of inhibiting zones formed around the well, due to the increasing of efficacious compounds in instant powders that can inhibit the growth of E.Coli bacteria.

Keyword : antibacterial activities, instant powder, Curcuma mangga Val, Acalyphaindica L.

\section{PENDAHULUAN}

Di negara berkembang seperti Indonesia, diare masih menjadi masalah utama dalam kesehatan baik pada anak-anak maupun orang dewasa. Frekuensi kejadiannya sebanyak 2-3 kali lebih banyak dibandingkan negara maju (Sari, 2005). Salah satu bakteri penting penyebab diare adalah Escherichia coli. Bakteri Escherichia coli merupakan bakteri gram negatif yang dapat menyebabkan gangguan pada tubuh apabila masuk ke tubuh berkisar $10^{6} \mathrm{sel} / \mathrm{ml}$ (Ahlquist \& Camileri, 2001).

Penyakit yang disebabkan oleh bakteri biasanya ditanggulangi dengan pemberian antibiotika. Antibiotika mampu menghambat pertumbuhan mikroorganisme lain atau bahkan membunuhnya. Setiap antibiotik beragam keefektifannya dalam melawan berbagai jenis bakteri. Pemakaian antibiotika dalam jangka panjang dapat menyebabkan sifat resistensi dari mikroorganisme terhadap antibiotik yang digunakan (Utami,2012). Paradigma tersebut memunculkan langkah alternatif untuk menggali senyawa lain yang mempunyai aktivitas antibakteri. Salah satu alternatif yang digunakan untuk mengatasi penyakit diare yang disebabkan Escherichia coliadalah dengan memanfaatkan bahan-bahan alam tumbuhan atau yang sering disebut dengan obat tradisional.

Menurut Dalimartha (2007) Kelebihan penggunaan bahan alam antara lain Lebih ramah 
Cahyaningrum, P.L.,Artini, N.P / Kesehatan Terpadu 2(1) (2018)

lingkungan, mudah didapatkan, murah, dan memiliki efek samping relatif lebih kecil. Pengolahan obat tradisional pada umumnya dengan cara direbus atau ditumbuk seperti jamu. 
Namun, pengolahan bentuk obat dalam bentuk jamu memiliki beberapa kendala yaitu jangka waktu simpan yang tidak terlalu lama dan kurang praktis dalam penyajiannya sehingga diperlukan pengolahan dengan cara lain yaitu kristalisasi untuk menghasilkan minumanserbuk instan. Pemanfaatan tumbuhan obat sebagai bahan baku dalam pembuatan minuman serbuk instan bertujuan diantaranya disamping kemudahan dalam penyajian juga diharapkan memiliki khasiat bagi kesehatan tubuh (Rengga dan Handayani, 2009). Beberapa tumbuhan obat yang dapat dimanfaatkan adalah temu mangga (Curcuma mangga Val.) dan anting-anting (Acalypha indica L.).

Temu mangga merupakan salah satu dari banyak jenis temu-temuan yang dimanfaatkan sebagai bahan baku obat-obatan. Temu mangga mengandung saponin, flavonoid dan polifenol (Hutapea, 1993), juga mengandung antioksidan alamiah, yaitu kurkuminoid (Sudewo, 2004), minyak atsiri, tanin, amilum, gula dan damar.Temu mangga ini sering digunakan dalam pengobatan tradisional diantaranya mengobati keputihan, diare, obat jerawat dan gatal-gatal (Rukmana, 2004). Temu mangga juga berpeluang sebagai obat infeksi yang disebabkan oleh mikroba patogen seperti C. albicans, S. aureus dan E. coli (Jawetz, et al., 1996).

Tanaman anting-anting (Acalypha indica L.) dikenal sebagai salah satu tanaman obat yang tumbuh di pinggir jalan dan kebun. Tanaman anting-anting sering dikenal dengan tanaman kucing-kucingan. Kandungan kimia dari tanaman anting-anting yang telah dilaporkan mengandung saponin, tanin, flavonoid, dan minyak atsiri (Azmahani et al. 2002). Sejak dulu masyarakat sering menggunakan tanaman ini untuk mengobati penyakit disentri basiler dan disentri атиеba, diare, malnutrisi, mimisan, muntah darah, buang air besar berdarah, buang air berdarah, malaria (Arisandi et al. 2008). Walaupun ekstrak etil asetat antinganting berpotensi sebagai antibakteri (Govindarajan, 2008). Namun, potensi sebagai antibakteri yang dikombinasi dengan temu mangga belum pernah dilaporkan.

Belum banyaknya literatur yang membahas tentang potensi antibakteri dari kombinasi temu manga dandaun anting-anting yang diolah dalam bentuk serbuk instan maka penulis memandang perlu untuk dilakukan suatu penelitian secara ilmiah tentang uji aktivitas antibakteri serbuk instan kombinasi temu manga dan daun antinganting.

\section{METODE}

Penelitian ini menggunakan dua rancangan penelitian, yaitu: deskriptif eksploratif dan eksperimental. Penelitian deskriptif eksploratif meliputi proses pembuatan serbuk instan temu mangga (Curcuma mangga val.) dan daun antinganting (Acalypha indica L.) sedangkan penelitian eksperimental dilakukan melalui uji daya hambat aktivitas antibakteri dengan menggunakan bakteri E.coli

\section{Bahan Penelitian.}

Bahan yang digunakan dalam penelitian ini adalah temu mangga (Curcuma mangga Val.), daun anting-anting (Acalypha indica L.) dalam keadaan segar, gula pasir dan air akuades. Penyiapan bahan meliputi, pengumpulan bahan, pembersihan dan penggerusan dengan menggunakan blender, penyaringan, pemanasan dengan penambahan gula pasir sehingga menjadi serbuk instan. Bahan-bahan kimia yang digunakan dalan penelitian ini adalah akuades, kertas saring Whatman no. 42, asam tanat, asam galat, pereaksi Folin Ciocalteu, etanol 96\%, etanol absolute, $\mathrm{Na} 2 \mathrm{CO} 37.5 \%, \mathrm{Na} 2 \mathrm{CO} 3$ jenuh dan larutan $\mathrm{DPPH}$ $0.2 \mathrm{Mm}$ dalam etanol 96\%, Escherichia coli (Laboratorium Mikrobiologi, Fakultas Teknologi Pertanian, Universitas Udayana), natrium sulfat anhidrat, aseton, Brain Heart Infusion (BHI) dan Mueller Hinton (MH).

\section{Alat Penelitian.}

Alat-alat yang digunakan dalam penelitian ini adalah alat-alat untuk pembuatan serbuk instan yaitu pisau, blender, pisau, saringan, baskom, pengaduk, wajan, kompor, ayakan, plastik, sendok dan timbangan. Sedangkan alat-alat untuk keperluan analisis yaitu cawan petri, tabung reaksi, erlenmeyer, inkubator, timbangan ohaus, mikropipet $1 \mathrm{ml}$, autoklaf, waterbathmagnetic stirre.

\section{Prosedur Kerja \\ Penyiapan Bahan.}

Sebanyak $1 \mathrm{~kg}$ temu mangga (Curcuma mangga Val.) dan $1 \mathrm{~kg}$ daun anting-anting (Acalypha indica L.) dikumpulkan dan dibersihkan dari kotoran yang menempel, dicuci dengan air mengalir.

\section{Pembuatan Serbuk Instan melalui Proses Kristalisasi.}

Pembuatan serbuk instan kombinasi rimpang temu mangga (Curcuma mangga Val.) dan daun anting-anting (Acalypha indica L.) menggunakan prinsip kristalisasi dengan tahapan:

\section{Penghalusan}

Temu mangga (Curcuma mangga Val.) dan daun anting-anting (Acalypha indica L.) yang sudah dicuci bersih kemudian dihaluskan dengan menggunakan blender hingga menjadi bubur dengan ditambahkan air selanjutnya disaring dengan menggunakan kain kasa steril. 


\section{Pemasakan/kristalisasi}

Pemasakan merupakan proses terakhir dari pembuatan serbuk instan kombinasi temu mangga (Curcuma mangga Val.) dan daun anting-anting (Acalypha indica L.). Pemasakan atau kristalisasi disini sampai terbentuk kristal dengan penambahan gula pasir.Gula pasir yang digunakan sebanyak 1 kg. Api yang digunakan adalah api kecil (suhu dibawah $100^{\circ} \mathrm{C}$ ) dan dengan pengadukan terusmenerus. Bentuk kristal yang telah didapat kemudian dihancurkan untuk kemudian disaring, sehingga mendapatkan serbuk instan kombinasi temu mangga (Curcuma mangga Val.) dan daun anting-anting (Acalypha indica L.) yang halus dan seragam.

\section{Pengeringan dan Pengayaan}

Serbuk yang telah dihancurkan, kemudian dikeringkan dan diayak hingga diperoleh serbuk instan yang benar-benar lembut. Untuk serbuk yang belum lolos ayakan, dapat dihancurkan lagi. Serbuk instan hasil pengayaan tersebut kemudian segera dikemas dalam kantong plastik ataupun toples.

4. Tahap Formulasi Serbuk Instan Kombinasi

Temu Mangga (Curcuma mangga Val.) dan Daun Anting-anting (Acalypha indicaL.)

Pada tahap ini dilakukan formulasi serbuk instan. Formulasi didasarkan pada hasil percobaan terhadap karakteristik mutu organoleptik dari minuman instan. Pada tahap ini, produk akhir hasil formulasi minuman adalah bentuk serbuk dengan perbandingan gula sesuai dengan perlakuan dalam penelitian ini. Selanjutnya dilakukan analisis uji aktivitas antibakteri terhadap bakteri Escherichia coli.

\section{Uji Aktivitas Antibakteri}

a.Bakteri Escherichia coli

Bakteri yang digunakan dalam penelitian ini terdiri dari kelompok bakteri negatif dengan menggunakan Escherichia coli.

\section{b. Pembuatan Nutrient Agar (NA)}

Nutrien agar ditimbang sebanyak 5,75 gram. Kemudian ditambahkan $250 \mathrm{~mL}$ akuades. Panaskan suspensi sampai agar-agar mnjadi matang. Lalu dimasukkan nutrient agar ke dalam tabung reaksi \pm $10 \mathrm{~mL}$. Sterilkan dengan autoclave pada temperatur $121^{\circ} \mathrm{C}$ selama 15 menit.

\section{c. Pembuatan Nutrient Broth (NB)}

Nutrien broth ditimbang sebanyak 2,6 gram. Kemudian ditambhkan sebanyak $200 \mathrm{~mL}$ akuades. Panaskan suspensi ini sampai nutrient broth menjadi matang. Lalu dimasukkan natrium broth ke dalam tabung reaksi $\pm 3-5 \mathrm{~mL}$. Sterilkan dengan autoclave pada temperatur $121^{\circ} \mathrm{C}$ selama 15 menit.

\section{d. Isolasi Mikroba}

Isolasi mikroba diawali dengan penyiapan media nutrient agar (NA) miring, kemudian dengan menggunakan alat ose diambil biakan bakteri dari isolat (stok kultur bakteri) yang tersedia di Laboratorium Mikrobiologi. Lalu diinkubasi pada inkubator pada suhu $37{ }^{\circ} \mathrm{C}$ selama 24 jam. Isolasi mikroba ini bertujuan untuk meremajakan bakteri yang terdapat isolat (stok kultur bakteri).

\section{e. Pembuatan Suspensi Bakteri}

Sebanyak satu ose bikan murni bakteri uji diinkubasi dalam mdia nutrient broth (NB) sebanyk $50 \mathrm{~mL}$ dan dimasukkn ke dalm erlenmeyer. Biakan ini kemudian diinkubasi pada temperatur $37{ }^{\circ} \mathrm{C}$ selama 24 jam. Selanjutnya biakan dapat digunakan dalam uji antibakteri.

\section{f. Uji Aktivitas Antibakteri}

Uji aktivitas antibakteri diawali dengan penyiapan cawan petri steril yang ditambahkan dengan $1 \mathrm{~mL}$ suspensi bakteri. Kemudian masukkan nutrien agar (NA) sebanyak $15 \mathrm{~mL}$ yang sudah dicairkan pada temperatur $40-44^{\circ} \mathrm{C}$. Cawan petri ini kemudian digoyangkan secara simultan untuk memperoleh suspensi bakteri yang homogen pada permukaan media nutrien agar.

Langkah selanjutnya adalah melubangi media agar yang telah disemaikan dengan bakteri penguji. Pengujian aktivitas antibakteri menggunakan metode difusi sumur (modifikasi Kirby Bauer). Masing-masing sampel dibuat dengan konsentrasi $20 \%, 40 \%, 60 \%, 80 \%$, dan $100 \%$ dimasukkan kedalam masing-masing lubang sebanyak $20 \mu \mathrm{L}$ lalu diinkubasi selama 24 jam pada suhu $37^{\circ} \mathrm{C}$ dan sebagai kontrol digunakan pelarutnya. Dalam uji ini, hasil positif ditandai dengan terbentuknya daerah bening disekitar sumur yang menunjukkan adanya penghambatan pertumbuhan bakteri (Ardiansyah, 2007).

\section{HASIL DAN PEMBAHASAN}

\section{Kristalisasi Temu Mangga dan Daun Anting- anting Menjadi Serbuk Instan}

Pada penelitian ini dihasilkan kombinasi temu mangga (Curcuma mangga val.) dan daun antinganting (Acalypha indica L.) berbentuk serbuk berwarna kecoklatan dan larut dalam pelarut air. Aromanya seperti ramuan herbal umumnya, yaitu beraroma seperti jamu dan berasa manis karena kandungan dari gula yang ditambahkan pada instan mangga (Curcuma mangga val.) dan daun antinganting (Acalypha indicaL.). Jumlah serbuk instan yang diperoleh sebanyak 840 gram. Hasil instan temu mangga (Curcuma mangga val.) dan daun anting-anting (Acalypha indica L.) disajikan pada Gambar 1 


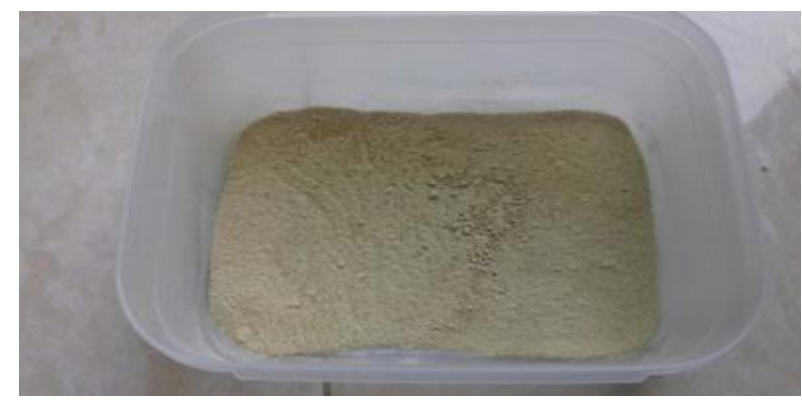

\section{Gambar 1. Serbuk Instan Temu Mangga (Curcuma mangga val.) dan Daun Anting- Anting (Acalypha indica L.)}

\section{Sifat Mikrobiologi Rimpang Temu Mangga (Curcuma mangga val.) dan Daun Anting- Anting (Acalypha indica L.) dengan Pengukuran Daya Hambat}

Untuk mengukur daya hambat dari instan temu mangga (Curcuma mangga val.) dan daun anting-anting (Acalypha indica L.) terhadap bakteri E.coli, terlebih dahulu instan diekstraksi dengan menggunakan pelarut berupa etanol dengan metode maserasi. Kemudian diekstraksi selama 1x24 jam dan dibuat kental dengan menggunakan rotary evaporator. Setelah diperoleh ekstrak kentalnya dilakukan pengujian daya hambat dengan menggunakan salah satu bakteri penyebab diare, yaitu E. coli yang merupakan salah satu bakteri gram negatif dengan menggunakan metode difusi sumur (modifikasi Kirby Bauer), dan konsentrasi sampel $20 \%, 40 \%, 60 \%, 80 \%$, dan $100 \%$. Hasil positif ditandai dengan terbentuknya daerah bening disekitar sumur yang menunjukkan adanya penghambatan pertumbuan bakteri (Ardiansyah, 2007).
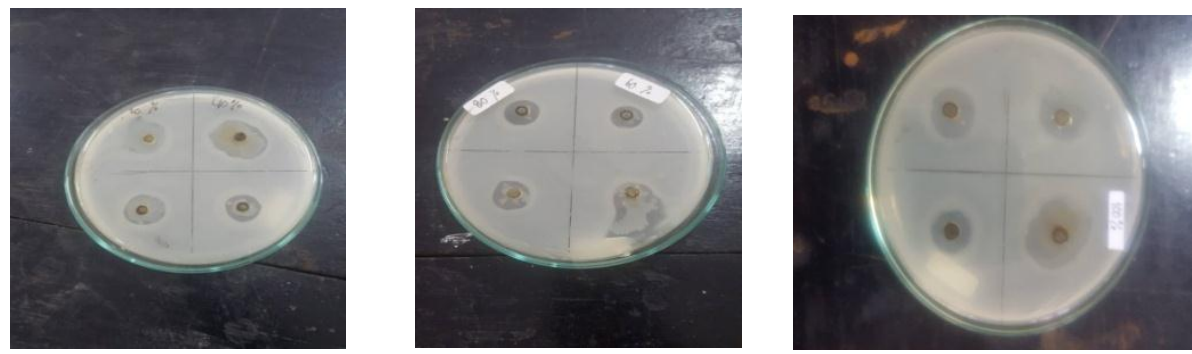

Gambar 2.Diameter Zona Hambat Instan Temu Mangga (Curcuma mangga val.) dan Daun Anting-Anting (Acalypha indica L.) terhadap E. Coli pada Konsentrasi 20\%,40\%,60\%,80\% dan $100 \%$.

Hasil pengujian dari ekstrak etanol instan temu mangga (Curcuma mangga val.) dan daun anting-anting (Acalypha indica L.)terhadap bakteri E coli, terlihat memiliki zona bening di konsentrasi $60 \%, 80 \%$, dan 100\% (Gambar 2). Diameter daya hambat ekstrak etanol instan temu mangga (Curcuma mangga val.) dan daun anting-anting (Acalypha indica L.). terhadap E. coli semakin meningkat bersamaan dengan meningkatnya konsentrasi ekstrak (Tabel 1). Hal ini menunjukkan bahwa senyawa aktif yang terdapat di dalam ekstrak etanol instan temu mangga (Curcuma mangga val.) dan daun anting-anting (Acalypha indica L.). memiliki aktivitas antibakteri dan mampu menghambat pertumbuhan bakteri E. coli dari golongan gram negatif.
Daya hambat ekstrak etanol instan temu mangga (Curcuma mangga val.) dan daun antinganting (Acalypha indica L.) $60 \%$ memiliki diameter zona terang $8 \mathrm{~mm}$ dan sifat kekuatan hambatan yang lemah, sedangkan instan dengan konsentrasi $80 \%$ sebesar $12 \mathrm{~mm}$, dan 100\% sebesar $14 \mathrm{~mm}$ dan respon kekuatan daya hambat antibakteri ini termasuk kategori kuat. Hal ini menunjukkan bahwa senyawa aktif yang terdapat didalam ekstrakinstan temu mangga (Curcuma manggaval.) dan daun anting-anting (Acalypha indica L.). memiliki aktivitas antibakteri dan mampu menghambat pertumbuhan bakteri E.coli dari golongan gram negatif. Hasil tersaji pada Tabel 1. 
Tabel 1. Hasil Pengujian Zona Hambat Serbuk Instan Temu Mangga (Curcuma mangga val.) dan Daun Anting-Anting (Acalypha indica L.) terhadap E. coli.

\begin{tabular}{lcc}
\hline \multicolumn{1}{c}{ Sampel } & Diameter Zona Terang & Respon Hambatan Pertumbuhan \\
\hline Blanko & - & Tidak ada \\
Instan $20 \%$ & $2 \mathrm{~mm}$ & Lemah \\
Instan $40 \%$ & $4 \mathrm{~mm}$ & Lemah \\
Instan $60 \%$ & $8 \mathrm{~mm}$ & Sedang \\
Instan $80 \%$ & $12 \mathrm{~mm}$ & Kuat \\
Instan $100 \%$ & $14 \mathrm{~mm}$ & Kuat \\
\hline
\end{tabular}

Keterangan :

Diameter zona hambat (Davis and Stout, 1971)

$$
\begin{array}{ll}
<5 & : \text { Lemah } \\
6-10 \mathrm{~mm} & : \text { Sedang } \\
10-20 \mathrm{~mm} & : \text { Kuat } \\
>20 \mathrm{~mm} & : \text { Sangat kuat }
\end{array}
$$

Berdasarkan tabel diatas, diketahui bahwa pada konsentrasi serbuk instan 60\%, $80 \%$ dan $100 \%$ dapat memberikan efektivitas antibakteri terhadap bakteri E.Coli. Ini membuktikan bahwa semakin tinggi konsentrasi serbuk instan temu mangga dan daun anting-anting yang diberikan, maka semakin besar pula diameter zona hambat yang terbentuk di sekeliling sumur.

Sebaran daya hambat kurang dari $15 \mathrm{~mm}$ tetap menunjukkan bahwa serbuk instan temu mangga (Curcuma mangga val.) dan daun anting-anting (Acalypha indica L.) memiliki kekuatan daya hambat yang kuat, dan bersifat daya hambat sangat kuat jika memiliki zona bening diatas $20 \mathrm{~mm}$. Sehingga serbuk instan temu mangga (Curcuma mangga val.) dan daun anting-anting (Acalypha indica L.) dapat digunakan sebagai salah satu produk herbal untuk mengobati diare dengan membunuh aktivitas mikrobiologi dari gram negatif E. coli.

Kandungan rimpang temu manga (Curcuma mangga val.) yang digunakan dapat bersifat sebagai daya hambat antibakteri karena mengandung saponin, flavonoid dan polifenol (Hutapea, 1993), juga mengandung antioksidan alamiah, yaitu kurkuminoid minyak atsiri, tanin, amilum, gula, dan damar. Temu mangga ini sering digunakan dalam pengobatan tradisional diantaranya mengobati keputihan, diare, obat jerawat dan gatal-gatal (Rukmana, 2004). Temu mangga juga berpeluang sebagai obat infeksi yang disebabkan oleh mikroba patogen seperti $C$. albicans, S. aureus dan E. coli (Jawetz, et al., 1996).

Sedangkan kombinasi lain berupa tanaman anting-anting (Acalypha indica L.) mengandung saponin, tanin, flavonoid, dan minyak atsiri yang dikenal sebagai salah satu tanaman obat yang digunakan untuk mengobati penyakit disentri basiler dan disentri amuba, diare, malnutrisi, mimisan, muntah darah, diare, dan malaria (Arisandi et al. 2008).

Menurut Ajisah (2004), selain faktor konsentrasi, jenis bahan antimikroba juga menentukan kemampuan menghambat pertumbuhan kuman. Dalam penelitian ini, adanya aktivitas antibakteri pada serbuk instan temu mangga dan daun anting-anting (Acalypha indica L.) diduga karena adanya kandungan senyawasenyawa berkhasiat seperti flavonoid, saponin dan tanin karena ketiga senyawa tersebut ada dalam masing-masing bahan dasar yang digunakan yaitu temu manggadan daun anting-anting.

\section{SIMPULAN}

Berdasarkan hasil penelitian dan pembahasan dapat disimpulkan sebagai berikut:

1. Serbuk instan kombinasi rimpang temu mangga (Curcuma mangga val.) dan daun anting-anting (Acalypha indica L.) terhadap pertumbuhan bakteri Escherichia coli menunjukkan adanya aktivitas antibakteri pada konsentrasi $80 \%$ dan $100 \%$ dengan daya hambat yang tergolong kuat sedangkan pada konsentrasi $60 \%$ tergolong sedang dan pada konsentrasi $20 \%$ dan $40 \%$ tergolong lemah sebagai antibakteri.

2. Peningkatan konsentrasi serbuk instan yang diberikan dari 20\%, 40\%, 60\%, $80 \%$ dan $100 \%$ menunjukkan semakin besar diameter zona hambat yang terbentuk disekeliling sumur, karena semakin meningkatnya senyawasenyawa berkhasiat dalam serbuk instan yang dapat menghambat pertumbuhan bakteri E.Coli. 


\section{DAFTAR PUSTAKA}

Ahlquist, D. A., M. Camilleri. 2001. Harrison's Principles of Internal Medicine, 15 edition, volume 1. Editors: E. Braunwald et al. The Mc Graw-Hill Companies, Inc. New York

Ajizah, A. 2004. Sensitivitas Salmonellathy pimurium Terhadap Ekstrak Daun Psidiumguajava L.J. Bioscientiae.1(1): 31-38

Ardiansyah,2007, Antimkroba dari tumbuha, postdoc Fellow Lab of Nutrition, Graduate Scholl of Agricultural Science, Tohoku University Sendai, Jepang

Arisandi Y, Andriani. 2008. Khasiat Tanaman Obat. Jakarta (ID): Pustaka Buku Murah.

Azmahani A, Somchti MN, Rosyilah AR. 2002. In Vitro Anti Bakterial and Anti Fungal Properties of Acalypha Indica (Kucing Galak). Proceedings of The Regiona Symposium on Environment and Natural Resources. Department of Biomedical Sciences, Faculty Medicine and Health Sciences, University Putra Malaysia, 43400 UPM Serdang, Selangor Darul Ehsan. Malaysia.

Dalimartha, S.2007. Atlas TumbuhanObat Indonesia.Jilid 2.TrubusAgriwidya : Jakarta

Davis, W.W and Stout, T.R. Disc Plate Methods of Microbiological Assay.Microbiology.22(4): 659-665
Govindarajan, A. Jebanesan, D. Reetha, R. Amsath, T. Pushpanathan, K. Samidurai. 2008. Antibacterial activity of Acalypha indica L. J. European review for medical and pharmacological sciences. 12: 299-302.

Hutapea, Johnny Ria DR., 1993. Inventaris Tanaman Obat Indonesia (II), 165, Badan Penelitian dan Pengembangan, Departemen Kesehatan Republik Indonesia, Jakarta

Jawetz, E., Melnick, J. L., danAdelberg, E. A., 1996, MikrobiologiKedoteran, Edisi XX, diterjemahkanolehNugroho, E. danMaulani R. F., 18-21, PenerbitBukuKedokteran EGC, Jakarta.

Rengga Pita W.D dan Handayani Astuti P, 2004. Serbuk Instan Manis Daun Pepaya Sebagai Upaya Mempelancar Air Susu Ibu. Jurnal Fakultas Teknik Kimia. Semarang: Unversitas Negeri Semarang

Rukmana, H. R. 2005. Bertanam Sayuran di Pekarangan. Yogyakarta; Kanisius

Sari, D. Y. 2005. Usai Tsunami, Diare Mengintai, (online),(http://cyberwoman.

cbn.net.id/detil.asp?kategori=Mother\&newsno =902, diakses 31 Maret 2017-06-09.

Utami, E.R .2012. Antibiotika, Resistensidan Rasionalitas Terapi. J. SAINTIS 1(1): 
Cahyaningrum, P.L.,Artini, N.P / Kesehatan Terpadu 2(1) (2018) 